\title{
KREATIVITAS DESAIN POSTER DALAM KOMPETISI DESAIN POSTER NASIONAL
}

\author{
Arif Priyono Susilo Ahmad \\ Jurusan Desain Komunikasi Visual, School of Design, BINUS University \\ Jl. KH. Syahdan No. 9, Palmerah, Jakarta Barat 11480 \\ arifpsa@yahoo.com
}

\begin{abstract}
Poster design competition/contest has become quite often held in Indonesia. Themes and organizers are varied, ranging from educational institutions, government, commercial and social institutions. On the one hand, the rise of this activity can be a trigger for the creativity of the nation, but on the other hand certainly it can cause turmoil in terms of the lack of exploration of ideas and applications. Too much information often overrides the hierarchy of information. Visual elements in a poster design contest overlap, compete for the attention of the viewers, so that we neglect the functions of persuasion. The functions of promotion poster is to communicate everything relating to the contest, including the contest theme, subtheme, explanations and background of the contest, organizers, prizes, attendees can participate, size and amount of work, limitations of work, deadlines, details of the jury, the address and number contest material delivery phone, website or email or phone number the committee can be contacted, and so on. Terms and conditions of the contest should be clearly communicated to the public. Poster contest that contains all of the terms and conditions of the competition will just be a communication medium and severe fatigue with too much text. Promotional poster contest should be able to convey a clear message and information about the contest, as well as be able to inspire and motivate potential competitors, so that the aim to capture ideas and a great poster design can be achieved. For this reason, the poster campaign of the poster competition must appear charming, unique, inspiring, creative, and nuanced in line with the theme.
\end{abstract}

Keywords: poster competition, poster design, hierarchy, persuasion

\begin{abstract}
ABSTRAK
Kompetisi atau lomba desain poster telah menjadi hal yang cukup sering dilaksanakan di Indonesia. Tema dan penyelenggaranya pun beragam, mulai dari lembaga pendidikan, pemerintahan, komersial dan lembaga sosial. Pada satu sisi, maraknya kegiatan ini dapat menjadi pemicu kreativitas anak bangsa, namun pada sisi yang lain tentu dapat melahirkan kegalauan dalam hal minimnya eksplorasi gagasan dan aplikasinya. Informasi yang terlalu banyak kerap mengesampingkan hierarki informasi. Elemen visual dalam desain poster lomba menjadi saling tindih, saling berebut meminta perhatian pemirsa, sehingga melupakan fungsi-fungsi persuasinya. Fungsi poster promosi adalah mengomunikasikan segala hal yang berkaitan dengan lomba, termasuk tema lomba, subtema, penjelasan dan latar belakang lomba, penyelenggara, hadiah, peserta yang dapat berpartisipasi, ukuran dan jumlah karya, batasan karya, tenggat waktu, detail juri, alamat dan nomor telepon pengiriman materi lomba, website atau email, panitia yang dapat dihubungi, dan sebagainya. Syarat dan ketentuan lomba harus jelas dikomunikasikan kepada masyarakat. Poster lomba yang berisi seluruh syarat dan ketentuan lomba hanya akan menjadi media komunikasi yang penat dan berat dengan teks yang terlalu banyak. Poster promosi lomba yang baik harus dapat menyampaikan pesan dan informasi yang jelas mengenai lomba, sekaligus dapat menjadi inspirasi dan memotivasi calon peserta lomba agar tujuan menjaring gagasan dan desain poster yang bagus dapat tercapai. Untuk itulah, poster promosi lomba poster harus tampil memesona, unik, inspiratif, kreatif, dan bernuansa senada dengan temanya.
\end{abstract}

Kata kunci: lomba poster, desain poster, hierarki, persuasi 


\section{PENDAHULUAN}

Poster adalah media komunikasi visual yang sangat popular. Hampir semua lapisan masyarakat mengenal keberadaan poster. Sifat dan karakternya menjamin efektivitas dalam menyampaikan pesan dan informasi kepada masyarakat. Seperti juga media komunikasi visual yang lain, poster juga harus tampil kreatif, unik dan komunikatif dalam kaitannya dengan 'persaingan' antar media komunikasi visual yang lain. Iklan majalah, iklan koran, billboard, brosur dan flyer, banner, dan sebagainya, adalah para 'pesaing' yang siap mengepung gerak dinamika masyarakat. Meski demikian, poster yang baik memiliki beberapa karakter khas, diantaranya:

- $\quad$ berukuran cukup besar (umumnya 50x70cm),

- $\quad$ ditempel atau dipajang di tembok/dinding di pinggir jalan,

- $\quad$ provokatif, informatif dan persuasif,

- 'berteriak', baik secara visual maupun dalam konteks dan gagasan,

- $\quad$ mudah terlihat, mudah terbaca dan mudah dipahami,

- memiliki unsur 'stopping power',

- $\quad$ unik dan berani,

- $\quad$ single message, apakah melalui visual atau teks,

- $\quad$ eksploratif dalam format, bahan, dan teknologi

Pendekatan penyampaian pesan lewat poster terjadi hampir di semua ranah lapisan masyarakat dan untuk kepentingan yang sangat luas. Mulai dari anak sekolah hingga perusahaan multinasional, mulai dari untuk kepentingan lomba antar RT hingga kampanye periklanan nasional, dari yang sosial hingga komersial. Poster telah menjadi bagian hidup masyarakat dalam menyampaikan informasi kepada bagian masyarakat yang lain. Salah satu hal yang kemudian membedakan poster yang satu dengan yang lain adalah kreativitas desain poster.

Sebagai media komunikasi visual popular, poster kerap diperlombakan atau disayembarakan. Tujuan sayembara desain poster beragam. Umumnya, penyelenggara lomba mencari ide-ide terbaik dari masyarakat untuk kepentingan tertentu. Seringkali, hasil desain lomba hanya sebatas diumumkan atau dipamerkan dalam sebuah forum khusus. Padahal, bila diperhatikan, poster pemenang lomba dapat diproduksi dan dipublikasikan secara luas kepada masyarakat agar gagasan-gagasan yang baik dalam poster tersebut 'teruji' dengan baik di masyarakat. Desain poster yang baik adalah efektif dan komunikatif dalam menyampaikan pesan dan kreatif dalam visualisasinya juga. Poster-poster event seni dan desain sering tampil ideal dan menarik, baik dari segi gagasan maupun eksekusi desain visualnya. Hal ini wajar, mengingat komunitas seni dan desain adalah para pemuja kreativitas dan citra estetika.

Poster Lomba Desain 1001 Maskot Majalah concept (gambar 1) dan poster pameran karya desain mahasiswa Desain Komunikasi Visual Institut Seni Indonesia (ISI) Yogyakarta berjudul 'KIDS CARENIVAL' adalah contoh poster yang ideal. Keduanya mampu menampilkan desain poster yang sangat komunikatif dan sekaligus menarik dalam visualisasinya. Pemirsa poster tersebut akan dengan mudah mengapresiasi poster-poster yang kreatif seperti itu. Namun, kedua contoh poster tersebut menjadi tidak terlalu istimewa ketika kita melihat komunitasnya adalah orang-orang kreatif. Desain poster pada kasus ini perlu nilai lebih disbanding yang lain. Robin Landa dalam bukunya 'Graphic Design Solutions', mengungkapkan bahwa bagaimanapun juga poster berfungsi menyampaikan pesan, maka pertama poster harus memiliki kemampuan menarik perhatian pemirsanya. Hal tersebut menjadi catatan khusus mengingat poster biasanya berada di lokasi, dimana para pemirsanya berlalu-lalang, bergerak dinamis. Sudah jelas bahwa tugas sebuah poster harus dapat secara efektif dan kreatif menarik perhatian pemirsanya, sebelum menyampaikan pesan persuasifnya. 


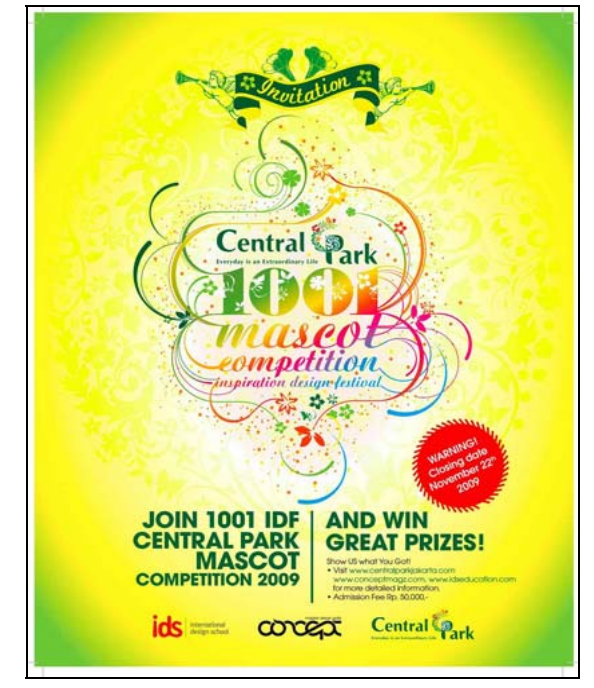

Gambar 1 Poster Lomba 1001 Maskot - majalah Concept

Poster ideal yang efektif pada umumnya jelas dan informatif, serta kreatif dalam mengajak.

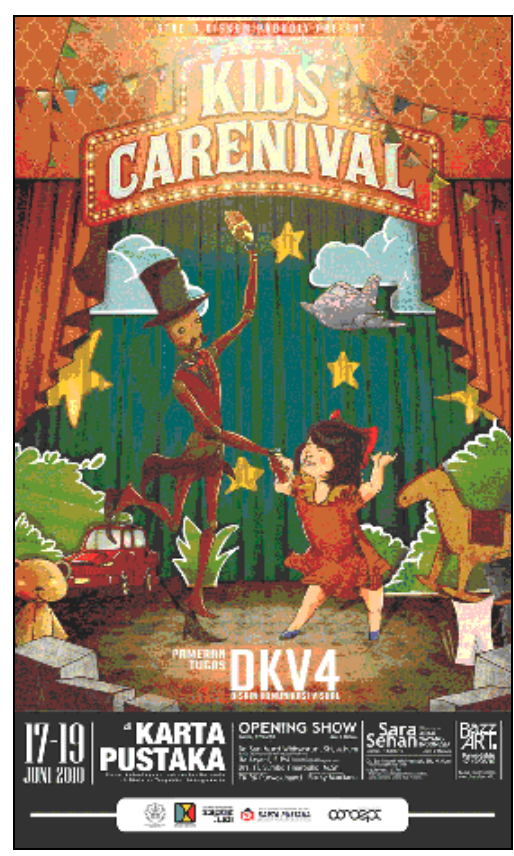

Gambar 2 Poster pamrean DKV ISI Yogyakarta.

Poster ideal berani bermain dan kreatif dalam menyampaikan informasi.

\section{METODE PENELITIAN}

Penulisan artikel ini menggunakan metode analisa formal. Penulis mengumpulkan bahanbahan desain poster dari lomba desain Poster melalui internet dan dokumentasi pribadi. Penulis mengumpulkan referensi mengenai desain poster pada buku-buku teks dan website. Penulis membuat analisa peran kreativitas dalam mendukung efektivitas desain poster serta bagaimana perkembangan poster event secara umum. 


\section{HASIL DAN PEMBAHASAN}

\section{Poster promosi lomba}

Dalam artikel ini, masalah dibatasi dengan meneliti desain poster pada lomba atau sayembara desain poster di Indonesia dengan beberapa sampel. Contoh-contoh kasus sebagian besar didapatkan dari internet dan karya penulis sendiri. Hal menarik dalam kasus ini adalah masih banyak ditemukan desain poster untuk mempromosikan lomba desain poster justru tidak memikat secara desain. Padahal wilayah komunitasnya sebagaian besar adalah orang-orang kreatif dan sebagian yang lain adalah masyarakat umum.

Mendesain poster tidak hanya berkait dengan masalah teknis dan estetika, namun juga harus memperhatikan peran kreativitas persuasinya. Masalah teknis yang dimaksud meliputi elemen dasar desain (garis, bidang, warna, tekstur, format, gambar, teks), prinsip desain (hirarki, unity, balance, emphasis, dll), gaya desain (design style), produksi dan teknologi. Masalah eksplorasi gagasan adalah hal yang juga penting, selain memberi kesan yang baik dan kredibilitas bagi poster itu sendiri atau penyelenggaranya, poster dengan desain dan gagasan yang kreatif dapat memberi inspirasi bagi masyarakat. Gabungan dari teknis dasar dan eksplorasi gagasan dapat membuat desain poster lebih berkarakter kuat.

Secara umum, desain poster untuk mempromosikan lomba desain poster memuat data-data informasi berikut:

- nama event/ lomba

- tema dan sub tema lomba

- headline

- visual utama (berupa gambar atau huruf)

- keterangan tema lomba

- siapa saja yang boleh ikut/ lingkup peserta

- siapa penyelenggara lomba

- hadiah lomba

- ketentuan dan syarat lomba

- deadline penyerahan materi/ karya

- tanggal dan tempat pengumumna pemenang

- alamat dan nomor telepon panitia

- alamat website dan email lomba

- para sponsor dan pendukung lomba

- nama contact person panitia, dan sebagaianya

Data-data awal tersebut sifatnya mutlak karena berisi informasi yang harus diketahui para peserta. Hal lain yang harus dilakukan adalah unsur kreativitasnya dalam mengembangkan konsep idenya dan bagaimana eksekusinya.

\section{Analisa kasus A: similarity}

Berikut adalah analisa kreativitas terhadap beberapa kasus desain poster untuk promosi lomba desain poster yang ditemukan penulis:

- gambar 3, poster lomba desain poster se-Indonesia dengan tema "Singgah ke Tanah Rencong”, LPM UNMUHA,

- gambar 4, poster lomba desain poster 'Islam Cinta Damai', Lazuardi Birru,

- gambar 5, poster lomba desain poster 'Doa untuk Indonesiaku’, Lazuardi Birru

- gambar 6, poster lomba desain poster HUT ke 8 Trans TV, 
- gambar 7, poster lomba desain poster, foto dan video K3L, Universitas Indonesia,

- gambar 8, poster lomba desain poster PIF

- gambar 9, poster lomba desain poster dan flyer, KPU,

- gambar 10, poster lomba desain poster 'Rhino Care'

- gambar 11, poster lomba desain poster 'Ramuan Tradisional Lintas Generasi’, Orang Tua

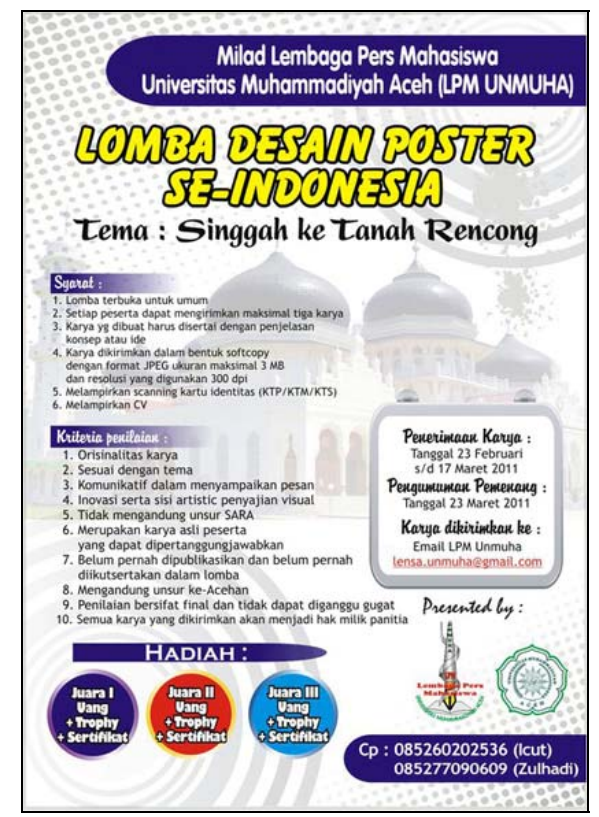

Gambar 3 Poster Lomba Poster UNMUHA.

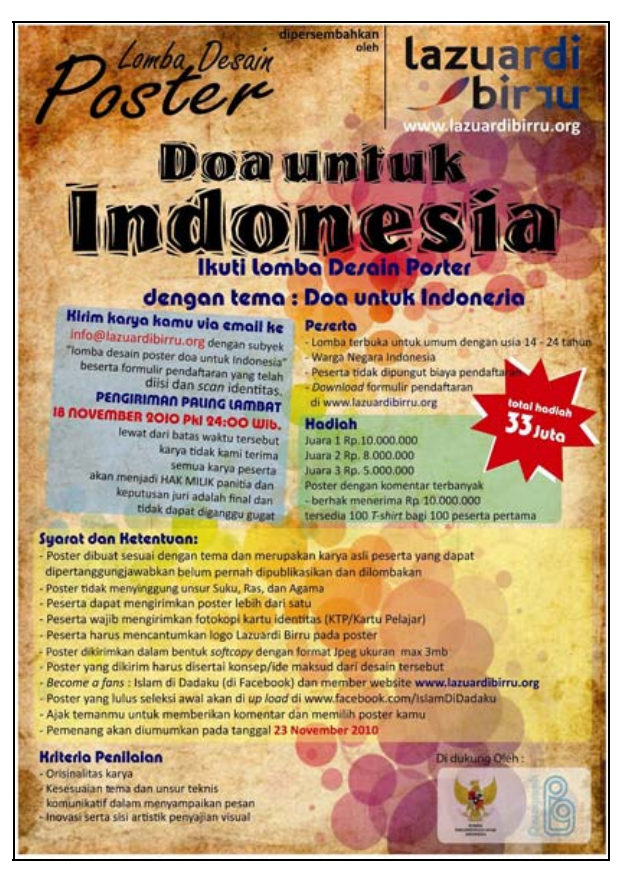

Gambar 5 Poster Lomba Poster Lazuardi Birru 2

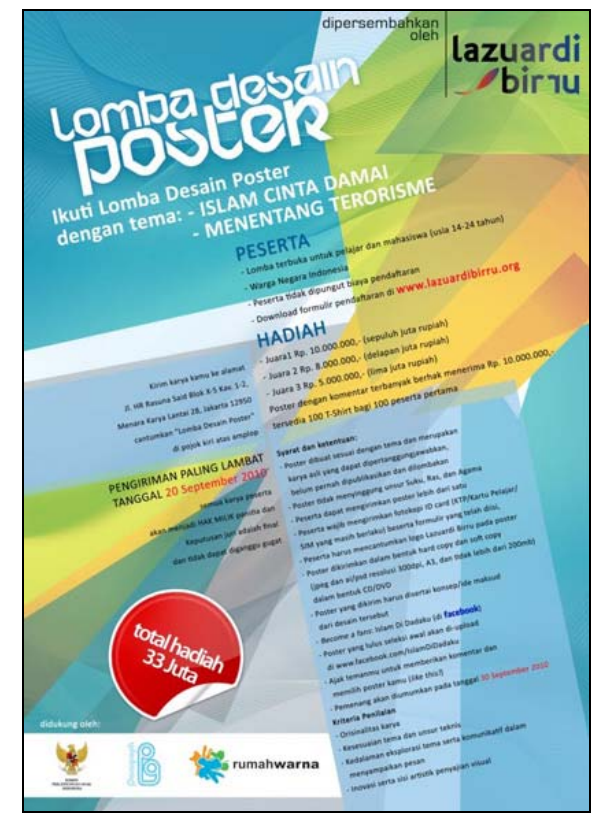

Gambar 4 Poster Lomba Poster Lazuardi Birru.

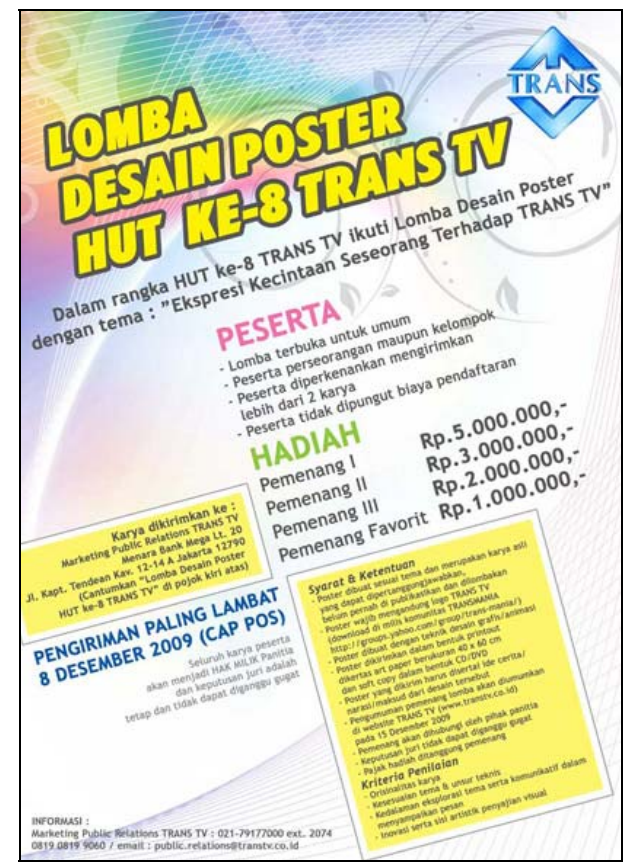

Gambar 6 Poster Lomba Poster Trans TV 


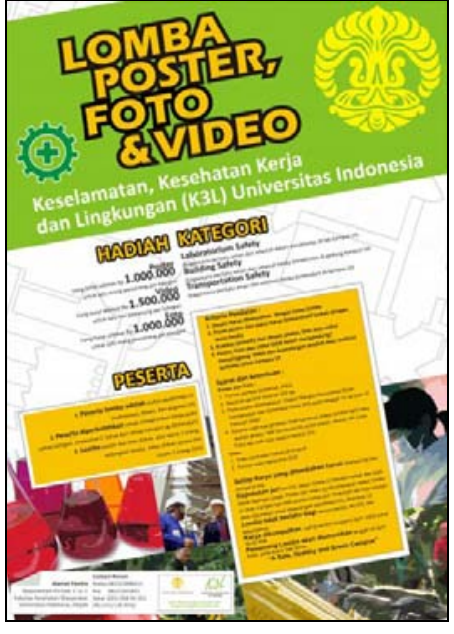

Gambar 7 Poster Lomba Poster K3L UI

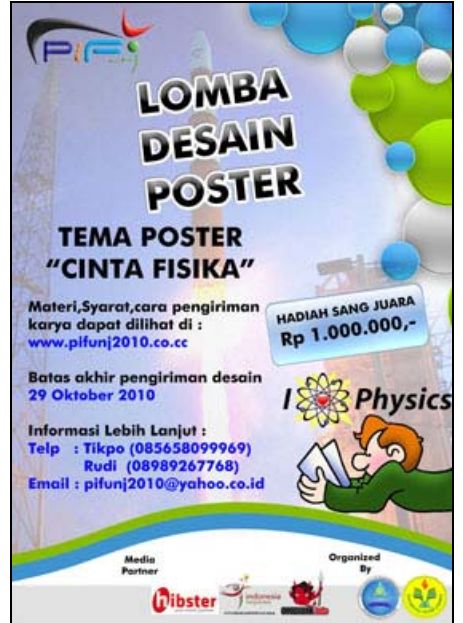

Gambar 8 Poster Lomba Poster PIF

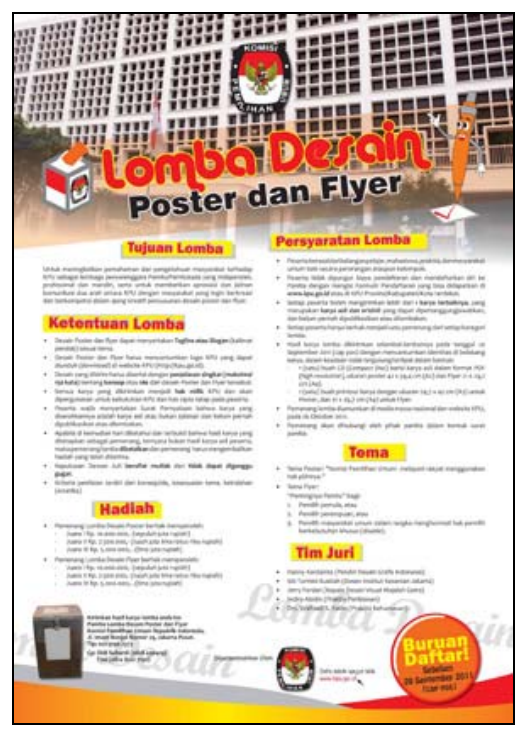

Gambar 9 Poster Lomba Poster KPK.

Tidak menyisakan space untuk eksplorasi ide

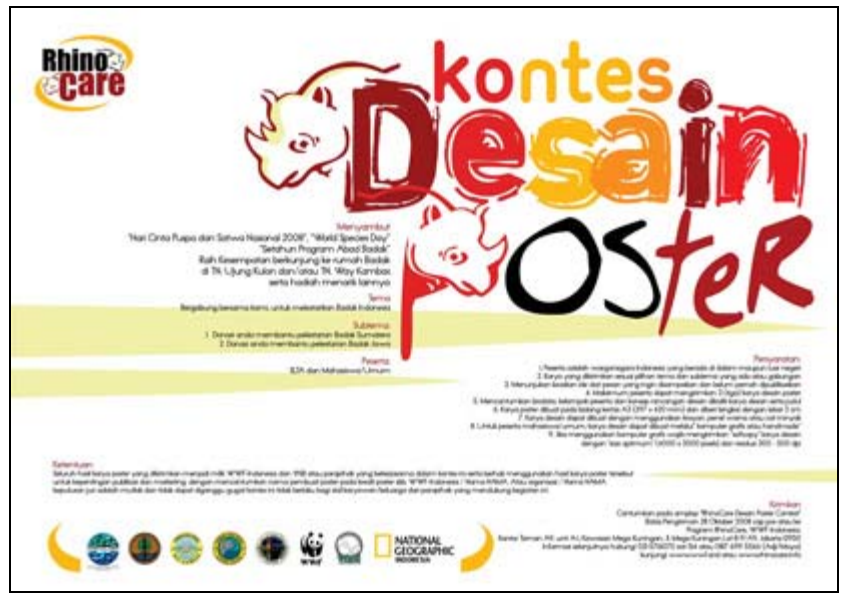

Gambar 10 Poster Lomba Rhino Care 
Pada poster lomba poster 'Rhino Care', satu-satunya kesan yang membantu memvisualisasikan tema adalah sketsa kepala badak. Di luar itu, mulai dari warna, tipografi dan visualisasi tidak terlihat mendukung tema lomba. Desain tipografi judul lomba ditempatkan cukup strategis dan dominan, sehingga sangat mudah dilihat pemirsa. Tidak ditemukan ide kreatif dalam poster tersebut.

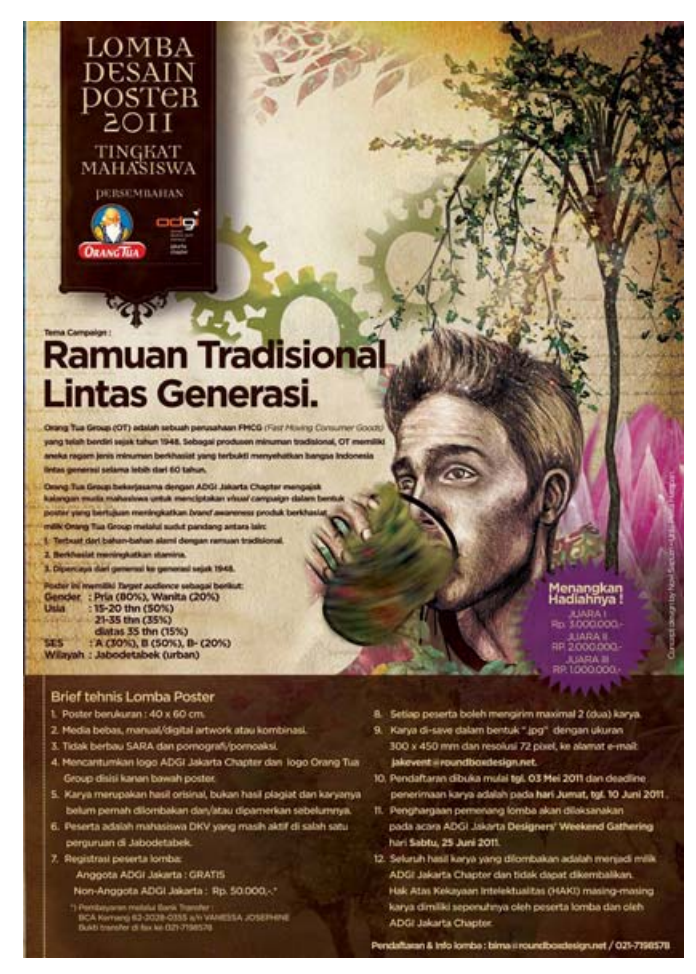

Gambar 11 Poster Lomba ‘Orang Tua’ \& ADGI

Timothy Samara dalam “Design Elements: A Graphic Style Manual”, setidaknya menyebut beberapa hal prinsip yang menjadikan sebuah desain disebut baik, yaitu:

- $\quad$ memiliki konsep yang jelas

- $\quad$ desain itu mengkomunikasikan sesuatu, bukan sekedar dekorasi

- $\quad$ secara hirarkis, ada satu hal yang ditonjolkan (emphasis)

- $\quad$ simple namun jelas

- $\quad$ desain yang universal, bukan untuk pribadi

- $\quad$ desain adalah visual, maka harus nyaman di mata

- $\quad$ dinamis dan asimetris

- $\quad$ desain adalah image

Poster promosi event lomba poster yang baik juga tidak lepas dari pemikiran tersebut di atas. Dari kasus tersebut di atas, terdapat banyak hal yang luput dari perhatian dalam mendesain poster yang baik. Umumnya poster tersebut memiliki kesamaan (similarity) kelemahan dalam visual dan gagasan/ eksplorasi ide:

- $\quad$ hanya mengutamakan faktor informasi yang berlebihan, bahkan mendominasi ruang,

- Jenis huruf dan warna tidak mendukung tema lomba

- $\quad$ Struktur layout formal, kecuali poster gambar 4, 6,7 dengan struktur miring (similar)

- $\quad$ Tidak ada headline (teks perangsang komunikasi)

- $\quad$ Tidak terdapat visual utama yang tematik, kecuali poster gambar 10 dan 11 
Pada poster lomba poster 'Ramuan Tradisional Lintas Generasi', nuansa warna coklat alami cukup membantu tema lomba, yaitu tradisional. Namun penggambaran figur manusia terlalu ilustratif dan bergaya sketsa menjadikan kesan suram warna coklat menjadi semakin suram. Jenis huruf pada tema lomba dan aksen warna ungu cukup membantu kesan kekinian (lintas generasi). Selain itu, struktur tipografi pada teks terlalu menyita tempat yang tersedia. Maka yang terjadi adalah desain visual yang terkesan berdesak-desakan.

\section{Analisa kasus B: eksplorasi visual}

Berikut adalah studi kasus pada desain poster event lomba poster dalam kaitannya dengan eksplorasi, sebagai berikut:

- $\quad$ gambar 12, poster lomba desain logo Yayasan Batik Indonesia

- gambar 13 dan 14, poster lomba desain poster DEEP Indonesia 2008

- gambar 15, poster lomba desain poster DEEP Indonesia 2010

- gambar 16, poster lomba desain poster DEEP Indonesia 2011

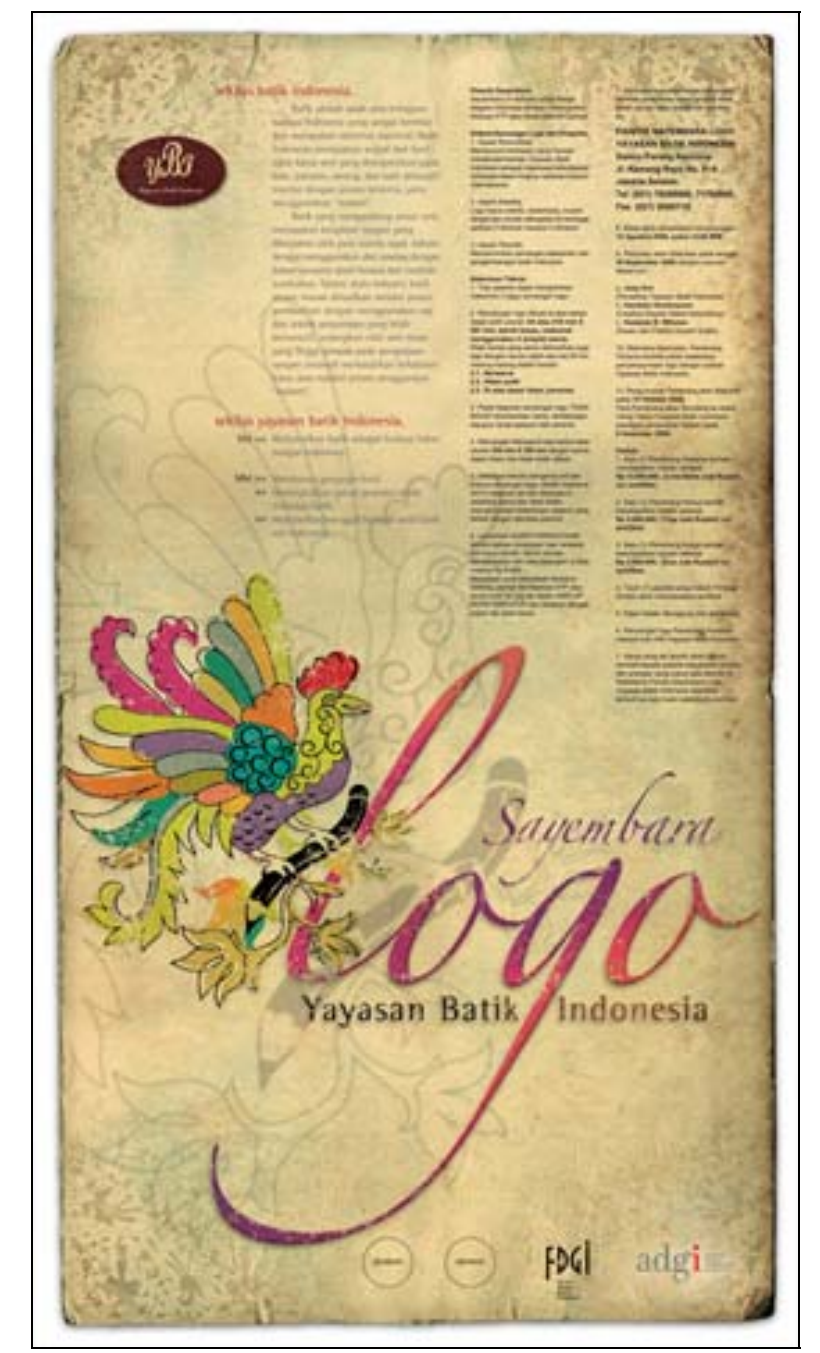

Gambar 12 Poster Lomba Logo Yayasan Batik Indonesia 
Pada poster lomba desain logo Yayasan Batik Indonesia, dominasi visual sangat berhasil. Ilustrasi burung bergaya motif batik diletakkan menyatu dengan teks 'Sayembara Logo Yayasan Batik Indonesia' dan ditempatkan di bagian bawah poster. Struktur teks dibuat rapi dan terjaga kualitas tipografinya dalam hal keterbacaannya (readability). Nuansa warna kecoklatan dan corak kertas tua pada latar belakang (background) sangat membantu dalam menunjukkan kesan batik. Kemudian format ukuran yang cukup ekstrim vertical, memperkuat kekhasan desain poster tersebut. Kesan warna coklat dan kusam sekaligus menjadikan mood desain secara keseluruhan menjadi terlihat kotor dan kurang anggun.
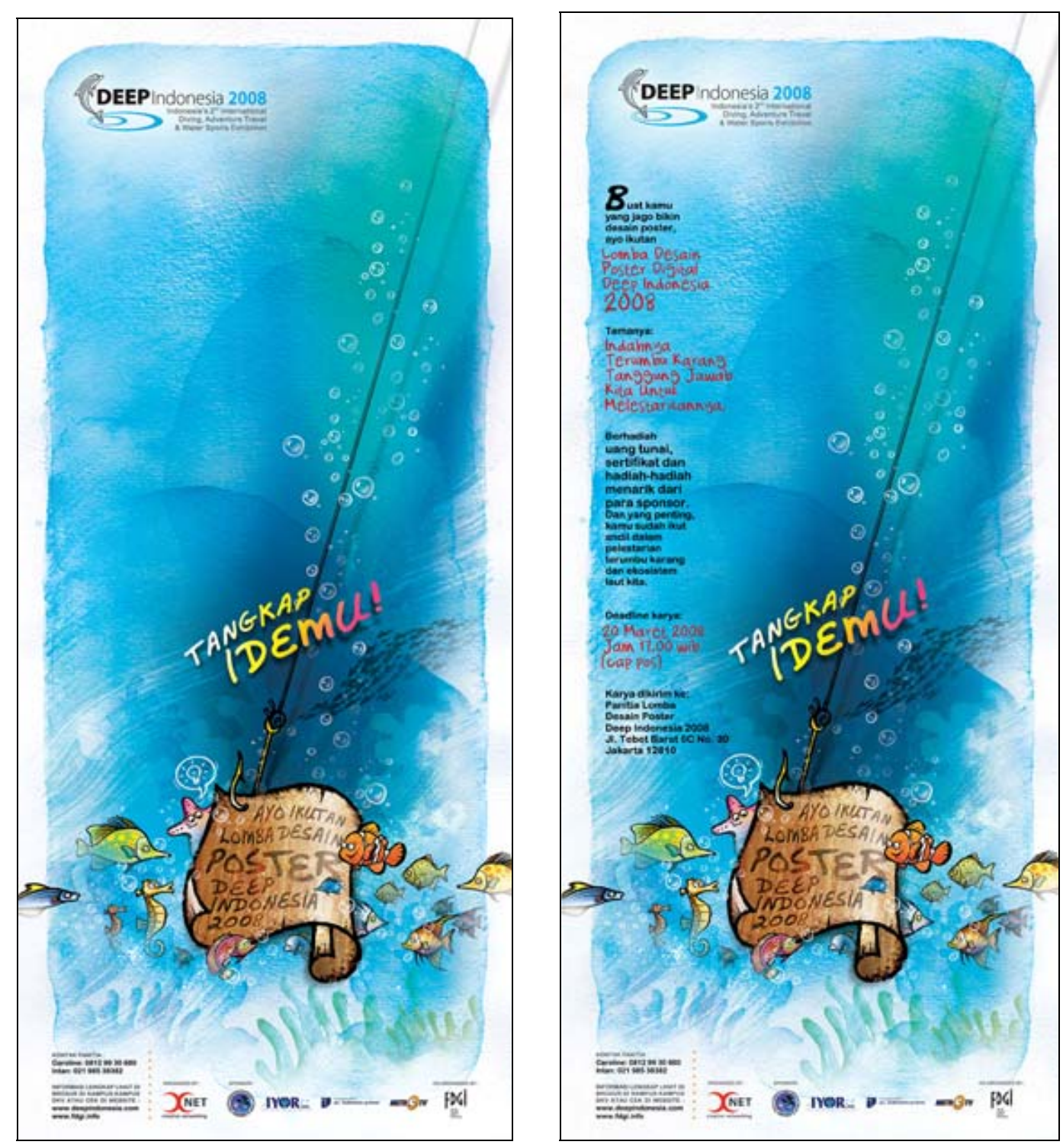

Gambar 13 \& 14 Poster Lomba Poster Deep Indonesia 2008

Poster lomba desain poster DEEP Indonesia 2008 (gambar 13 \& 14) terlihat menarik dari segi format yang memanjang vertikal, dari ilustrasi kartunal yang ringan ceria. Headline 'Tangkap Idemu' sangat relevan dengan pesan lomba, yaitu mengajak masyarakat membuat desain poster dalam rangka kepedulian terhadap terumbu karang. Visual menggambarkan secarik kertas bertuliskan 'Ayo ikutan Lomba Desain Poster DEEP Indonesia 2008' dalam kaitan kail di kedalaman laut dan dikelilingi 
beragam jenis ikan yang lucu-lucu. Ruang di bagian atas poster sengaja disisakan sebagai bagian ruang bebas (free space) memberi kesan keleluasaan dan kedalaman. Ruang tersebut dibiarkan kosong dan diisi dengan ilustrasi gelembung-gelembung buih air laut. Poster pertama berfungsi sebagai teaser, dan poster kedua dengan layout yang sama diposisikan sebagai poster informasi. Poster kedua menempatkan teks yang cukup panjang di baian kiri tersusun vertikal di bagian kiri poster tanpa mengganggu ruang kosong di sebelahnya. Meskipun ide poster tidak terlalu istimewa, namun secara keseluruhan, poster tersebut sangat menarik perhatian.

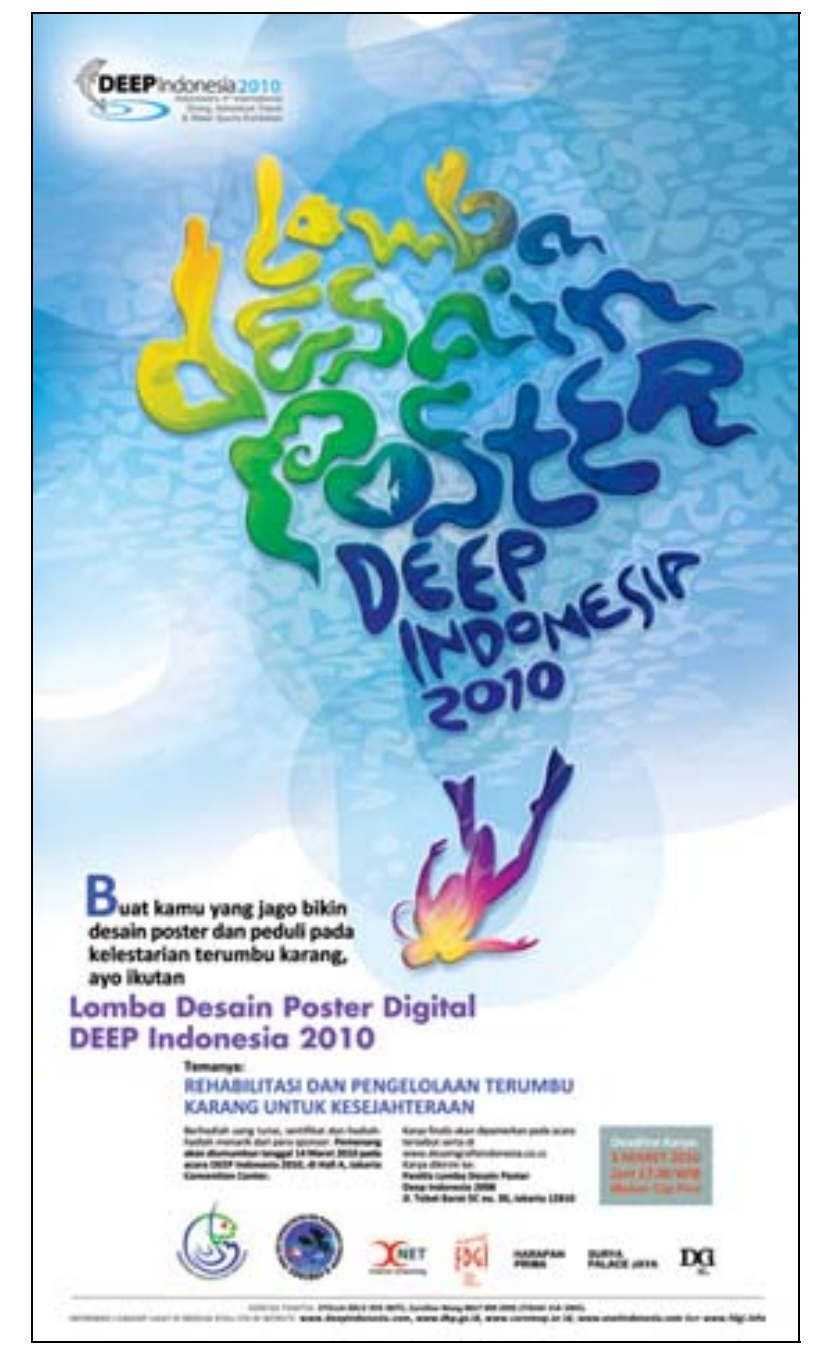

Gambar 15 Poster Lomba Poster Deep Indonesia 2010

Poster lomba desain poster DEEP Indonesia 20010 (gambar 15) memiliki format vertikal. Yang menarik dalam poster ini adalah eksplorasi judul lomba dengan memodifikasi tipografi menjadi berkesan seperti alur liuk air. Visualisasi tipografi menjadi berfungsi sebagai visual utama cukup menarik. Meskipun tanpa headline yang kuat, desain poster tersebut mampu menarik perhatian. Nuansa biru dan putih bersih menambah kesan modern dan muda sesuai dengan sasaran khalayaknya. 


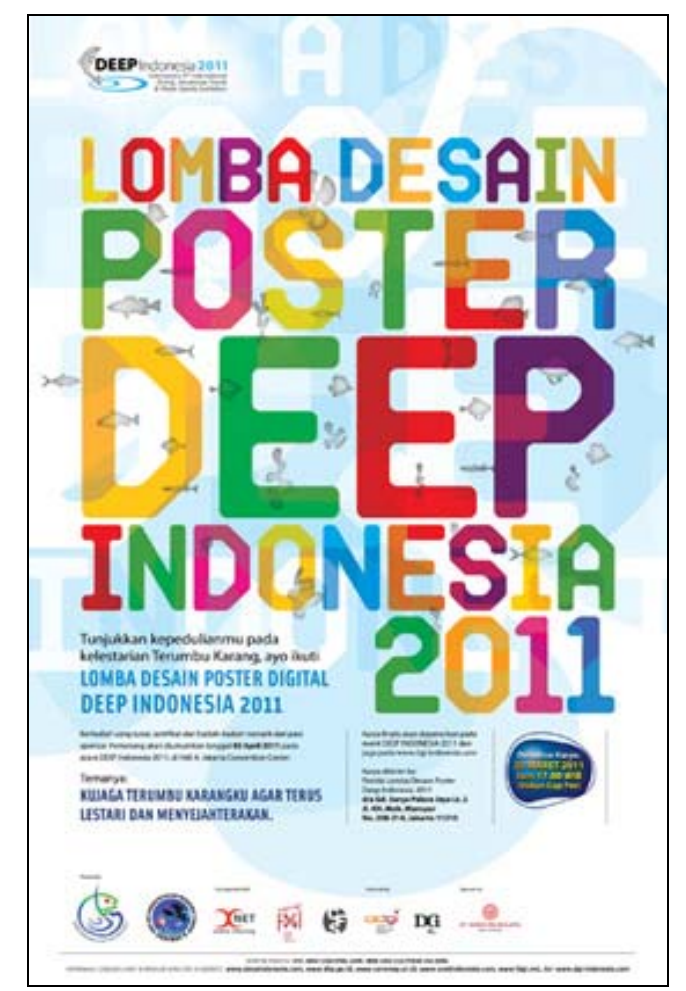

Gambar 16 Poster Lomba Poster Deep Indonesia 2011

Poster lomba desain poster DEEP Indonesia 2011 (gambar 16) memiliki format vertikal dan senada dengan poster DEEP Indonesia 2010. Pendekatan modifikasi tipografi juga senada dengan poster sebelumnya. Kekuatannya adalah warna-warna tipografi yang sangat kuat dan menggoda untuk diperhatikan. Tidak ditemukan konsep ide yang kuat dalam poster tersebut. Poster ini memberi contoh bahwa salah satu fungsi poster adalah 'berteriak'.

\section{Analisa kasus C: poster serial}

Berikut adalah studi kasus pada desain poster event lomba poster dalam kaitannya dengan melihat kasus eksplorasi desain dalam poster serial (gambar 17, seri poster promosi lomba desain poster Senyum 'Ayo Ngguyu’ DKV Binus University, 2010). Poster terdiri dari 4 seri, yaitu poster pertama sebagai pembuka informasi utama 'Postermu, Senyumku', poster kedua sebagai pengingat tanggal akhir pengumpulan karya, poster ketiga pengumuman finalis lomba, dan poster keempat adalah pengumuman pemenang lomba.

Secara garis besar, struktur layout dan komposisi poster tidak berubah, cenderung bergaya formal dan rapi. Selain headline berwana merah terang yang cukup sederhana 'Postermu, Senyumku', yang menarik dalam desain tersebut adalah unsur visual yang dominan. Visual berupa foto close up seorang model yang tampak tegang, kaku dan serius (pada versi 1) menggambarkan konsep berseberangan (juxtaposition) dengan tujuan lomba poster. Visual tersebut menjadi faktor utama dalam keseluruhan seri poster. Dalam poster kedua hingga keempat, secara gradual visual mimik model berubah-ubah sesuai dengan pesan dalam poster. Dalam poster keempat yang mengumumkan para pemenang lomba, mimik berubah menjadi ceria seolah menggambarkan kebahagiaan dan kelegaan. 


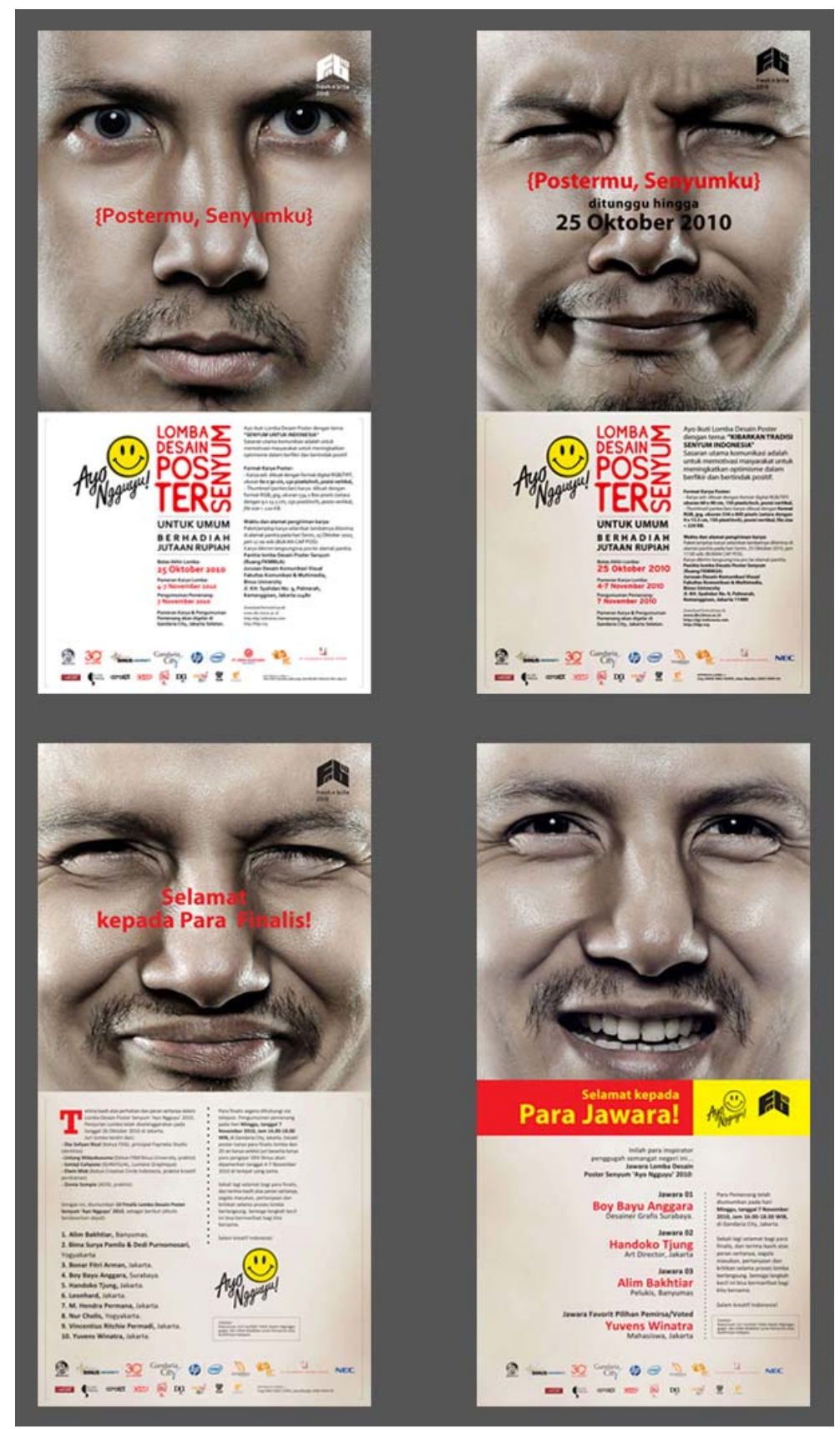

Gambar 17 Seri Poster Lomba 'Poster Ayo Ngguyu'

\section{Kelemahan dan Kelebihan}

Poster bertujuan menarik perhatian dan intens menyampaikan pesan kepada khalayak sasarannya. Poster promosi event lomba poster Senyum di atas, berhasil menjawab peran kreatifnya sekaligus peran komunikasinya. Kreatif karena visual desainnya, dan komunikatif karena menyampaikan pesan dan informasinya jelas dan teratur. Meskipun demikian, efektivitas dan eksplorasi desain poster tersebut masih dalam taraf gagasan yang bersifat umum dan aman. Tidak ada sesuatu yang mengejutkan dalam pemilihan visualnya maupun struktur desainnya. Struktur dasarnya bahkan sangat sederhana, hanya dengan memanfaatkan blocking yang dominan pada setengah bagian atas ukuran poster. Gagasan dan desain strukturnya masih terbuka untuk dikembangkan lagi. 


\section{SIMPULAN}

Desain Poster pada lomba desain poster memiliki peran yang penting. Di satu sisi, peran tersebut adalah peran mengirim atau menyampaikan informasi bagi calon peserta lomba. Dengan perannya tersebut, maka poster harus tampil informatif dan jelas menjelaskan komponen dasar perlombaan, seperti penyelenggara lomba, tema lomba, hadiah, tenggat waktu, syarat dan ketentuan, serta konfirmasi lebih lanjut tentang lomba (nomor telepon \& alamat panitia). Disamping itu, desain poster lomba juga harus mampu menggambarkan nuansa tema lomba, sehingga desain poster mampu menjadi inspirator sekaligus motivator bagi calon peserta lomba. Ketidakpahaman penyelenggara terhadap makna pengadaan lomba desain poster dan kurangnya wawasan mengenai desain, seringkali menjadi pemicu tidak berhasilnya menyampaikan informasi tentang lomba dengan baik. Pada akhirnya, desain poster untuk lomba desain poster tampil tidak menarik dan hanya menampilkan informasi teknis mengenai lombanya saja. Maka, penulis berharap, para penyelengara lomba desain poster dapat bekerja sama dengan konsultan desain grafis atau periklanan dalam merencanakan penyampaian pesan melalui media poster.

Struktur layout standar, tampak kaku dan monoton
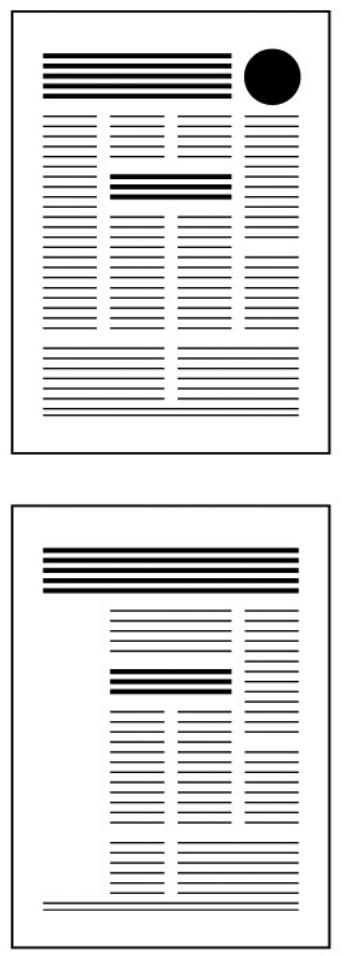

Gambar 18 Perbandingan struktur dasar layout
Struktur layout dengan emphasis yang baik.
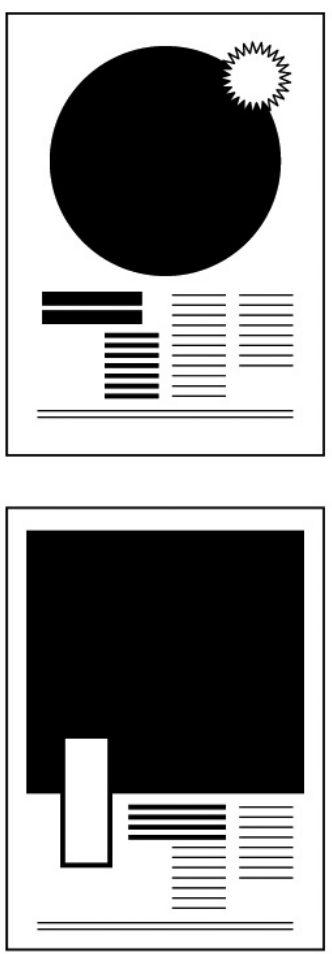

Selain baik dalam struktur dasar layout dan prinsip-prinsip desain, desain poster yang baik seharusnya mampu tampil kreatif, persuasif dan mendorong pemikiran kreatif bagi para pembacanya, khususnya calon peserta lomba. Desain poster yang baik harus mampu memberi inspirasi bagi masyarakat. Desain poster yang baik memiliki konsep atau ide yang akan memberikan kesan yang baik dan tak terlupakan bagi pemirsanya. Konsep dan ide yang menarik dapat digali dari sisi struktur layout dan desainnya atau dari eksplorasi temanya. 


\section{DAFTAR PUSTAKA}

Ambrose, G., \& Harris, P. (2005). Layout. Lausanne, Switzerland: AVA Publishing SA.

Landa, R. (2006). Graphic Design Solutions. New York: Thomson Delmar Learning.

Muller-Brockman, Josef, Muller-Brockman, Shizuko. (2004). History of the Poster. New York: Phaidon.

Samara, T. (2007). Design Elements - A Graphic Style Manual. Beverly: Rockport.

Rustan, S. (2009). Layout - Dasar dan Penerapannya. Jakarta: Gramedia Pustaka Utama.

http://dgi-indonesia.com/lomba-desain-poster-2011-tingkat-mahasiswa/

http://olongdesign.wordpress.com/2009/11/21/lomba-desain-poster-hut-ke-8-trans-tv/

http://forumbadak.files.wordpress.com/2008/10/lomba_poster_badak.jpg

http://photos-h.ak.fbcdn.net/photos-aksnc1/v2676/178/31/1258486111/n1258486111_368095_1874946.jpg

http://lazuardi-birru.blogspot.com/2010/08/lomba-design-poster.html

http://www.kpu.go.id/index.php?option=com_content\&task=view\&id=6620 